\title{
Biometric Authentication Based Automated Ration Disbursal for Public Distribution System
}

\author{
Shripad V Deshpande, Harikrishnan.R, Siddarth S Biraj
}

\begin{abstract}
This paper proposes a novel application for automating the Public Distribution System. The Government of India supplies essential commodities for everyday use like food grains (rice, wheat), kerosene (fuel for cooking) etc. to a large number of people by an elaborate machinery called Public Distribution System (PDS). This system currently works on manual processes. In this work, it is proposed that Smart Automated Ration Disbursal System (SARDS) using IoT replace the manual processes in PDS. This system consists of Embedded Controllers for online biometric authentication of the consumer, smart measuring for accurate disbursal of the commodities and real-time updating of data on the server. A prototype system to demonstrate its working is built using Arduino and Raspberry Pi controllers. An automatic dispensing system for solid as well as liquid commodity is fabricated and interfaced with the controllers using solenoid valves and sensors. Robust feedback is built into the system using sensors for accurate disbursal of material and detection of theft. Finally, experimental results showing accuracy of delivery of material and time required to process one consumer request are tabulated and analyzed. This system, when deployed in actual field, is expected to be operational $24 x 7$ and ensure safe, secure, fast and corruption-free distribution of Ration commodities to the general public
\end{abstract}

Index Terms: AutomatedRation shop, Automatic dispenser, Digital India, E-Governance, IoT application

\section{INTRODUCTION}

Due to large population in India, public distribution of Ration commodities in this country is not an easy task. Food ministry in Government of India manages this system. In India, approx. 1.21 billion (29.8\%) people live Below Poverty Line (BPL) and are dependent on a monthly supply of commodities from the Ration shop [1]. The country can progress and flourish only when the food safety to all the citizens of the country is ensured. Food safety essentially means availability of adequate quantity and quality of food commodities at the right time, at standard rated prices, especially for the people who are in the lower economic strata. Food Corporation of India (FCI) that was established in 1951, acquires, stores food commodities and releases a pre-defined quota every month through the PDS network for supplying to

Revised Manuscript Received on December 05, 2019

* Correspondence Author

Shripad V Deshpande, Electronics and Telecommunication Engineering, Symbiosis Institute of Technology (SIT), Symbiosis International Deemed University (SIDU), Pune, India.

Harikrishnan.R *, Electronics and Telecommunication Engineering, Symbiosis Institute of Technology(SIT), Symbiosis International Deemed University (SIDU), Pune, India.

Siddarth S Biraj, Electronics and Telecommunication Engineering, Symbiosis Institute of Technology (SIT), Symbiosis International Deemed University (SIDU), Pune, India. public at relatively lower cost [2].

Ration card is an authenticated document issued by Government of India to every family. This card acts as address/identity proof for a person authorizing him/her to receive monthly allocation of food grains from the Ration shop. This card includes identity of every member of the family like name, age, gender and photograph. According to number of members in the family, government decides the allocation of ration in proportionate ratio [3] [4].

The proposed SARDS runs $24 X 7$ without the need for any human operator and helps the consumers to buy their ration in convenient way by making the whole process automatic, efficient, smart, easy to use and reliable right from authentication to dispensing of food commodities. It ensures that correct quantity of the ration goods reach the common people in a reliable and transparent manner. This system includes smart features like smart measuring based on sensor feedback, three level authentication of consumer password, RFID [5] and biometric [6] of consumer, web camera to detect quality of food grains and also keeping consumer updated with all the information regarding availability of ration in the shop and SMS alert regarding ration delivered to the consumer.

Contribution of this work is demonstration of automated operation of food grain disbursal under PDS. The experiments prove that it is possible to eliminate all the manual steps being done in current system and replace the process by automation with reasonable speed of operation and accuracy of delivered quantity of goods. The authors also claim contribution that such a complete end-to-end integration of the whole process is demonstrated for the first time.

This paper is organized as follows - Section II summarizes existing systems used for public distribution of ration in India with their associated drawbacks. Section III gives details about recent published work in this field with observed gaps. Section IV elaborates proposed system in detail with associated hardware and software. Section V gives experimental setup used for trials and section VI gives experimental results with analysis. Finally, section VII summarizes the paper with conclusion and future scope.

\section{EXISTING SYSTEMS}

At present, in India, Rationing System falls into two broad categories - Traditional paper based Ration Book System and E-POS Machine System.

\section{A. Traditional Ration System}

Every family in India is provided with a simple colored paper based ration card booklet, 
the color of which decides the family's economic status. The demographic data of the family is included in the Ration Card. The family is associated with a fixed ration shop based on the vicinity of its residence and it can get its ration quota from the allocated shop only. Getting the monthly ration quota from the shop involves multiple manual steps like - the shop keeper physically checking authenticity of the consumer, checking the records in physical forms to find eligibility of the consumer regarding quantity of various commodity goods allocated to him/her, deciding on goods to be delivered, payment collection, weighing the deliverable goods, disbursal, updating the entries in log books to reflect all transactions in the day and sending the logbooks physically to authorities [7]. With so many manual steps and considering the large number of consumers associated with each shop, the whole process is prone to many issues and problems as listed below -

- Consumer has no idea of availability of goods in the shop before going to the shop. This leads to wastage of time and material.

- Corruption and Malpractices - e.g. Shopkeeper selling food grain stock in the open market at higher rate, quality of goods compromised etc.

- Processing speed slow - people have to wait for long time before getting ration.

- Cheating of consumers particularly

Illiterate-Overcharging, delivery of less quantity, substandard food grain. Human efforts are increased-So prone to errors.

- Consumer is attached to a particular shop from where he/she can buy the ration. This is inconvenient for consumers and many times leads to the ration going unutilized.

\section{B. E-POS System}

In the past few years, with the advent of new technology, particularly after Aadhar card coming into picture, PDS is improved by discarding the traditional paper based ration card system. In this system, called E-POS system, each consumer initially registers with the government of India giving all details about his/her family including the fingerprint impressions are recorded and uploaded in the central database. After online verification is done, the consumer is allowed to take the ration. The ration disbursal system is manual [7]. This system also has drawbacks like,

- Except authentication, rest all the system (mainly goods disbursal) is manual

- Time consuming process

- Human intervention required

\section{RELATED WORK}

In [8], Anshu Prasad, Aparna Ghenge, Sonali Zende, Prof. Sashikala Mishra \& Prof. Prashant Gadakh, have proposed "Smart Ration Card Using RFID, Biometrics and SMS Gateway". In this system, RFID tag is used that carries family members' details and the customer needs to show this tag at the ration shop to the shopkeeper. The user has to provide thumb impression on the biometric machine. Once the user is authenticated, the quantity of ration is given to customer in proportion to the total number of family members as per government policy. The information about the delivered quantity of ration is sent to the government directly and to the customer through SMS. The goods dispensing as well as selection of goods by user is a manual process and the authors have demonstrated the idea in simulated environment only.

In [3], Mohit Agarwal, Manish Sharma, Bhupendra Singh \& Shantanu have implemented "Smart ration card using RFID and GSM". In this system, the researchers used RFID tag that carries the family member details and customer needs to show this tag to the RFID reader. The microcontroller connected to the reader will checks user authentication. If the user is found authentic then the quantity of ration will be given to the customer accordingly. The authors have only discussed idea and no realization either on simulated environment or on hardware is done.

To avoid the problems associated with manual process, $\mathrm{K}$. Balakarthik proposed the "Cloud-Based Ration Card System using RFID and GSM Technology" in [9]. In this system, an efficient method for the user to buy the products in the ration shop by just flashing the card at the RFID reader is proposed. The user authentication is done by sending a random password text to the user mobile, which has to be entered in the keypad. The employee validates the purchase only after the details entered in the application matches the user's personal and purchase information. This work mentions only about authentication and does not mention about dispensing of goods.

In [2], Dhanashri Pingale, Sonali Patil, Nishigandha Gadakh, Reena Avhad \& Gundal S. Shave proposed a concept of "Web Enabled Ration Distribution and Corruption Controlling System". Here, the authors propose that grains are to be stored in a tank, and when the tank is filled, the quantity is updated in web server. The shopkeeper can access this website whenever a customer requires the ration. The user has to enter the product and quantity using a keypad and LCD display connected to the computer, which has the information of every person already in the database. The user is expected to get accurate quantity of required goods. Available quantity of goods in ration shop is again updated in server. The authors have presented only conceptual idea about GUI and web interface.

\section{A. Drawbacks of Existing Systems}

- Customer having no knowledge about availability of the ration in the shop.

- Corruption and Malpractices. E.g., the shopkeeper sells stock in the open market, overcharging particularly to illiterate customers, selling sub-standard goods etc.

- Due to the manned operations, the ration shop is open only a few hours in a day leading to overcrowding and hence slow processing. Customers spend a lot of time at the shop and majority of the time just waiting in long queue.

- Ration shopkeeper may declare "No Stock available" even when such is not the case.

- The Ration shops are not able to meet the requirements of all the customers due to point 3 above [2].

\section{PROPOSED SYSTEM}

To overcome the problems mentioned above, a novel idea called Smart Automated Ration Disbursal System (SARDS) is proposed. This proposed system consists of an automated ration-dispensing unit similar to 
24X7 ATM machine. To get entry into the ration shop, the consumer must already have a smart card issued by Govt. if India.

The SARDS consists of two parts - first, User Interface Module (UIM) consisting of GUI screen and keyboard and web interface and second, called Automatic Dispensing Module (ADM) consisting of electromechanical assembly for automatic dispensing of ration goods.

The User Interface Module (UIM) does three-level authentication of the consumer. It asks the user to enter user name and password to do first level of authentication; it then reads the consumer's Smart Ration Card and does second level of authentication. Moreover, in the third level, user's fingerprint is scanned and sent to centralized Aadhar card database [10] to authenticate the biometric information [6]. Once user is authenticated, a GUI screen shows the ration goods allocated to the user. The user selects the type and quantity of food commodity, goes through payment gateway to finish payment and then proceeds to the second part of the system i.e. Automatic Dispensing Module (ADM). The UIM also consists of GSM module for sending SMS alerts to consumer, which makes communication between consumer and Government completely transparent.

The Automatic Dispensing Module (ADM) dispenses the requested quantity of ration through an automatic electro-mechanical dispenser. In this prototype model for demonstration, two dispensers are used: one for solid material (e.g. wheat, rice etc) and another for liquid (e.g. Kerosene, oil etc.). The flow of material from the dispenser container is controlled using a electromechanical solenoid valves [11]. The time for which the valve is kept open is controlled in proportion to the weight (or volume if it's liquid) of the material to be dispensed. The time is also configurable for different grains and in case of liquid; the time is a function of viscosity of the liquid.

The system has un-manned operation, working $24 \times 7$, hence customers are able to purchase the ration material at their convenience rather than waiting in long queues. This system being fully automatic, it provides ration material accurately without human error.

In addition to the above, some safety and security features have also been implemented. An IR sensor detects whether there is a sack below the dispenser before starting to dispense the material. If the user tries to pick up the sack during dispensing then the load cell sensor detects reduction of weight in spite of dispensing in progress and immediately stops dispensing, beeps an alarm and sends an alert message to appropriate authorities. Another feature includes a web camera to detect which food grain is present in the hopper and show the image to the consumer so that he/she is sure about the grain that is being dispensed.

\section{A. Technical Block Diagram of SARDS}

Refer Figure 1 for the Block Diagram of SARDS. Arduino Mega and Raspberry Pi 3 [12] are used as main processors to perform all the computational functions in this system. Arduino Mega controls the automatic dispensing assembly with the help of solenoid valves to dispense accurate quantity of material to the consumer. Solid material is measured by its weight with the help of load cell sensor and liquid material is measured by sensing flow with the help of ultrasonic sensor. A delay controls opening and closing of the valve, which decides the specific quantity of selected material to be delivered [13].

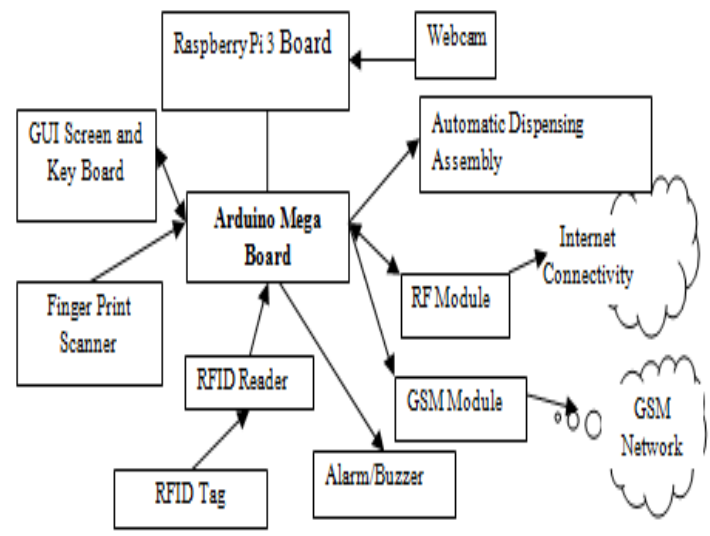

Fig. 1. Technical Block Diagram of SARDS. Arduino Mega is used as a main processor connected to all the peripherals. Raspberry $\mathbf{P i}$ is used for interfacing with camera.

The Arduino board is connected to RFID reader, fingerprint scanner, automatic dispensing system, GSM module, Wifi module (for internet connectivity), alarm indicator, and a GUI screen. The webcam is interfaced with Raspberry Pi 3. The two processor boards are connected through serial communication link [14].The GUI screen and keyboard are connected with the Arduino Mega through serial communication link. The automatic dispensing assemblies are driven directly by Arduino Mega Board through Relay Driver.

\section{B. General Process Flow of PDS and SARDS}

Figure 2 shows the Overall Process Flow of PDS. The blocks in blue color are not part of SARDS; but are pre-requisites for SARDS to work 


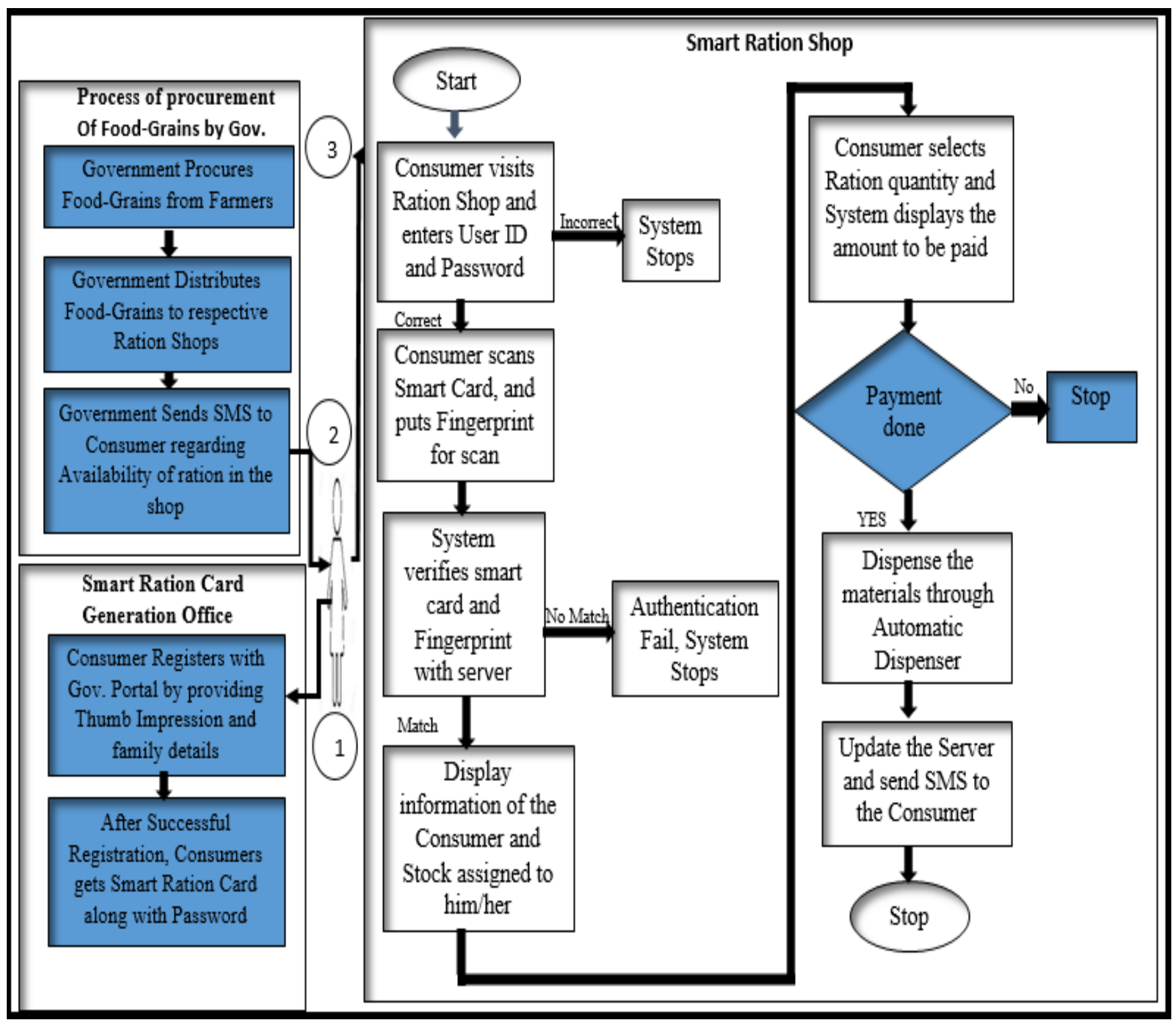

Fig. 2 General Process flow of PDS (overall) and SARDS (excluding blue colored boxes). The process steps 1, 2 and 3

\section{C.Working Principle of SARDS}

indicate how the consumer interacts with the system.

Before the consumer uses this system, it is assumed that he/she has already received a valid smart ration card along with user Id and password from the Government. Once the consumer registers with the government agency, he/she will start getting regular messages every month regarding availability of ration in the shop. After getting the message, consumer can visit the ration shop.

At the ration shop there is three-level authentication process done by UIM. At the first level, the consumer has to loginto the system with username and password. In the second level, consumer has to scan RFID card [8] and in the third level, the consumer puts fingerprint for scan. All the data is sent to the centralized Aadhar card server where authentication is completed.

Once authentication is successful, the UIM shows all the details of the family members and quantity of items allocated to the family. The consumer needs to select the ration items and quantity that he/she wishes to purchase. The system checks whether the quantity and material selected by the consumer is available or not. If the selected quantity is available then UIM checks whether the ADM has correct food grain with the help of web camera and then allows the consumer to pay the amount through payment gateway.

After the payment is done,UIM sends the list of items and quantity to be delivered to ADM. The ADM instructs the user to keep the bag below the hopper. When the IR sensor detects presence of bag below the hopper, the ADM actuates the solenoid valve so that the grain starts flowing. The approx. time for which the flow should continue, is pre-configured based on the type of grain and quantity. The load cell placed below the platform is used in a feedback loop to stop the flow of food grain as soon as required weight is detected in the bag. Similarly for dispensing of liquid material, consumer keeps his/her container/bottle below the funnel of the dispenser. The timing of opening of the funnel is controlled based on the viscosity of the liquid and the quantity [13].

After dispensing of the required material to the consumer, system will update the server and send SMS to the consumer.

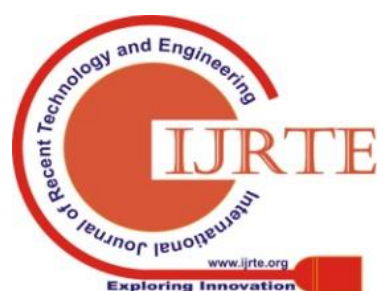


In addition to this, a Mobile App is also developed which the consumer can use any time to check the availability of ration in the shop as well as the quantity for which he/she is eligible.

\section{EXPERIMENTAL SETUP}

\section{A. Hardware Part}

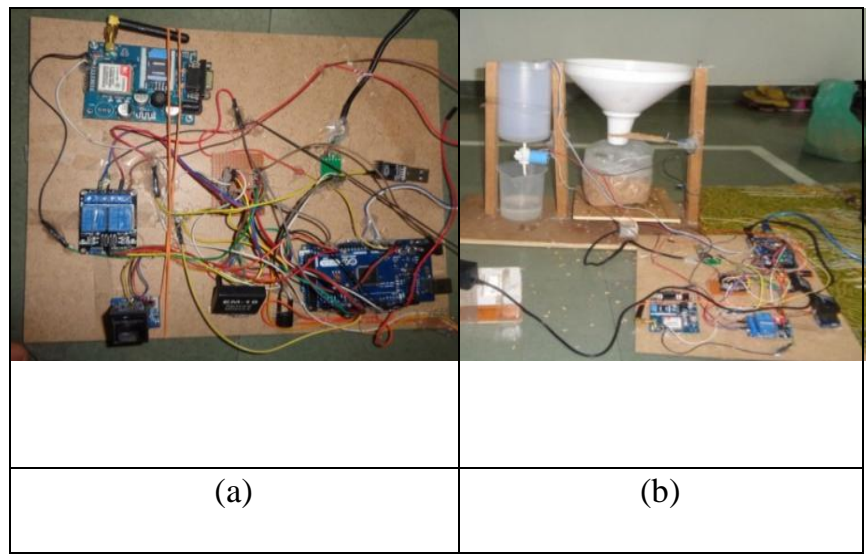

Fig. 3. Hardware Realization of Smart Automatic Ration Disbursal System (a) Main Processor Board and (b) Automatic Dispensing Module (Solid and Liquid material)

The hardware setup is created as per the block diagram in Figure 1. The UIM consisting of Arduino Mega board, RFID Reader, Fingerprint scanner, GSM Module, IR sensor, Ultrasonic sensor, Push-Pull Solenoid valve, RO Solenoid valve, Load cell and Web Camera along with Raspberry Pi 3 is setup to make the complete SARDS.

\section{B. Software Part}

The software consists of modules -

- Arduino code: Main software for handling GUI, authentication, interfacing with sensors and actuating the solenoid valves of the dispensing module. This code is implemented in Arduino code.
- Raspberry Pi code: for getting image from web cam and sending the image to Arduino. This code is implemented using Python [12].

- Web interface software consisting of HTML for the front end and the backend implemented using MySQL database and PHP. This code runs on PC [14].

- A Mobile App has also been developed using Mobile App Inventor.

C. Configuration used for experiments

- Only one valid user is created with RFID card for testing.

- Wheat is used as solid material for dispensing.

- Water is used in place of oil for testing with liquid dispensing.

\section{EXPERIMENTAL RESULTS}

- Solid material dispensing was tested with 10 trials each for $250 \mathrm{gm}$ and 500 gm quantity. The results are tabulated in Table $1 \&$ Table 2 . The weight measurement done with the load cell and actual measurement done in the shop using weighing machine is compared. The proposed system is found to give fairly accurate results in terms of dispensing of solid material. The results are shown graphically in Table 1 and 2

- Liquid material dispensing was tested with 10 trials each for $100 \mathrm{ml}$ and $200 \mathrm{ml}$ quantity of plain water. The results are tabulated in Table3and Table 4. The quantity measurement done for the dispensed liquid is compared with the expected value. The proposed system gives fairly accurate results in terms of dispensing of liquid material. The results are shown graphically in Table 3 and 4

\section{A.Comparison of manual and automatic dispensing of solid material}

The system was tested with solid material of $250 \mathrm{gm}$ and 500 gm

Table- I. Results for solid material dispensing of 250 gm

\begin{tabular}{|c|c|c|c|c|c|}
\hline Trial No. & $\begin{array}{l}\text { Expected Quantity } \\
\text { (gm) }\end{array}$ & $\begin{array}{l}\text { Actual Quantity } \\
\text { by using load cell } \\
\text { (gm) }\end{array}$ & $\begin{array}{l}\text { Actual Quantity } \\
\text { by using weighing } \\
\text { machine } \\
\text { (gm) }\end{array}$ & $\begin{array}{l}\text { Percentage accuracy } \\
\text { by using load cell } \\
(\%)\end{array}$ & $\begin{array}{l}\text { Percentage accuracy } \\
\text { by using weighing } \\
\text { machine } \\
(\%)\end{array}$ \\
\hline 1 & 250 & 246.4 & 246.78 & 98.56 & 98.71 \\
\hline 2 & 250 & 242.6 & 243.00 & 97.04 & 97.20 \\
\hline 3 & 250 & 242.4 & 242.60 & 96.96 & 97.04 \\
\hline 4 & 250 & 248.6 & 248.98 & 99.44 & 99.59 \\
\hline 5 & 250 & 249.9 & 250.04 & 99.69 & 100.02 \\
\hline 6 & 250 & 247.4 & 248.00 & 98.96 & 99.20 \\
\hline 7 & 250 & 248.0 & 247.68 & 99.20 & 99.07 \\
\hline 8 & 250 & 245.4 & 246.60 & 98.16 & 98.64 \\
\hline 9 & 250 & 238.6 & 240.02 & 95.40 & 96.01 \\
\hline 10 & 250 & 239.4 & 239.02 & 95.76 & 95.61 \\
\hline
\end{tabular}

Table- II Results for solid material dispensing of $\mathbf{5 0 0} \mathbf{~ g m}$ 
Biometric Authentication Based Automated Ration Disbursal for Public Distribution System

\begin{tabular}{cccccc}
\hline Trial No. & $\begin{array}{l}\text { Expected Quantity } \\
(\mathbf{g m})\end{array}$ & $\begin{array}{l}\text { Actual Quantity } \\
\text { by using load cell } \\
(\mathbf{g m})\end{array}$ & $\begin{array}{l}\text { Actual Quantity } \\
\text { by using weighing } \\
\text { machine } \\
(\mathbf{g m})\end{array}$ & $\begin{array}{l}\text { Percentage accuracy } \\
\text { by using load cell } \\
(\boldsymbol{\%})\end{array}$ & $\begin{array}{l}\text { Percentage accuracy } \\
\text { by using weighing } \\
\text { machine } \\
(\boldsymbol{\%})\end{array}$ \\
\hline 1 & 500 & 497.40 & 498.80 & 99.48 & 99.76 \\
2 & 500 & 493.20 & 492.40 & 98.64 & 98.48 \\
3 & 500 & 499.00 & 499.01 & 99.80 & 99.80 \\
4 & 500 & 479.80 & 480.00 & 95.96 & 96.00 \\
5 & 500 & 485.60 & 485.72 & 97.12 & 97.14 \\
6 & 500 & 496.70 & 498.20 & 99.34 & 99.64 \\
7 & 500 & 498.90 & 499.02 & 99.78 & 99.80 \\
9 & 500 & 487.70 & 487.28 & 97.54 & 97.46 \\
\hline
\end{tabular}

Table- III. Results for liquid material dispensing of $100 \mathrm{ml}$

\begin{tabular}{cccc}
\hline Trial No. & $\begin{array}{l}\text { Expected } \\
\text { quantity } \\
(\mathbf{m l})\end{array}$ & $\begin{array}{l}\text { Actual quantity } \\
\text { delivered(ml) }\end{array}$ & \multicolumn{1}{l}{$\begin{array}{l}\text { Accuracy } \\
(\%)\end{array}$} \\
\hline 1 & 100 & 95.4 & 95.4 \\
2 & 100 & 95.3 & 95.3 \\
3 & 100 & 98.4 & 98.4 \\
4 & 100 & 99.9 & 99.9 \\
5 & 100 & 99.6 & 99.6 \\
6 & 100 & 99.2 & 99.2 \\
7 & 100 & 97.0 & 97.0 \\
8 & 100 & 97.2 & 97.2 \\
9 & 100 & 98.0 & 98.0 \\
10 & 100 & 98.0 & 98.0 \\
\hline
\end{tabular}

Table- IV. Results for liquid material dispensing of $200 \mathrm{ml}$

\begin{tabular}{cccc}
\hline Trial No. & $\begin{array}{l}\text { Expected } \\
\text { quantity } \\
(\mathbf{m l})\end{array}$ & $\begin{array}{l}\text { Actual quantity } \\
\text { delivered }(\mathbf{m l})\end{array}$ & $\begin{array}{l}\text { Accuracy } \\
(\%)\end{array}$ \\
\hline 1 & 200 & 199.20 & 99.60 \\
2 & 200 & 197.40 & 98.70 \\
3 & 200 & 197.40 & 98.70 \\
4 & 200 & 198.50 & 99.25 \\
5 & 200 & 199.20 & 99.60 \\
6 & 200 & 196.60 & 98.30 \\
7 & 200 & 199.40 & 99.70 \\
9 & 200 & 199.00 & 99.50 \\
10 & 200 & 198.20 & 99.10 \\
\hline
\end{tabular}

\section{B.Comparative analysis}

Table 1 shows maximum accuracy of $99.96 \%$ with load cell and $100.02 \%$ with weighing machine. Similarly, Table 2 shows maximum accuracy of $99.78 \%$ with load cell and $99.80 \%$ with weighing machine. The results of the system can be further improved by using high accuracy sensor. In addition, the resolution of the sensor and frequency at which the sensor data is sampled affects the accuracy. The delay in operation of the plunger of the solenoid valve to stop the material dispensing has impact on the accuracy. Fine-tuning of this operation by factoring the delay while giving command to the solenoid will further improve the accuracy of delivered quantity close to $100 \%$. The maximum accuracy from Table $3 \& 4$ for $100 \mathrm{ml}$ and $200 \mathrm{ml}$ is 
$99.9 \%$ and $99.6 \%$ respectively. Here the quantity is measured by the time for which the valve is kept open. No load cell is used. This can be improved by using an accurate flow meter in the dispensing pipe. Essentially, there are many parameters, which are controllable to bring the accuracy to desiredlevel.

\section{Screen Shots of GUI screen}

Figure 4 (a) and (b) show the pictures of various GUI Screen shots -

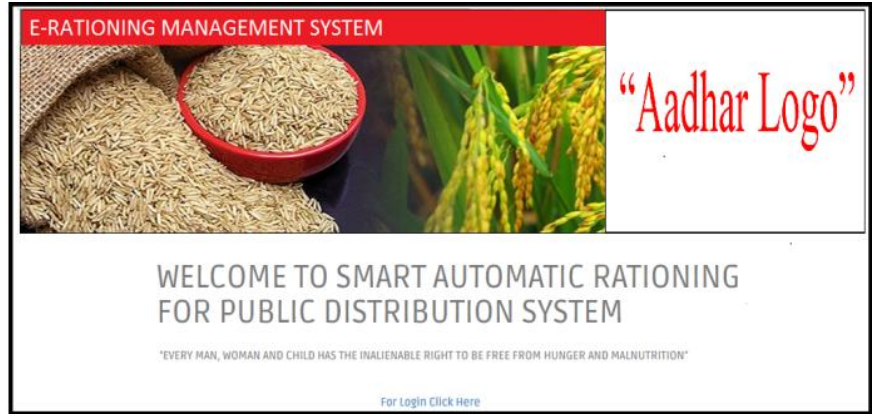

(a) Homepage

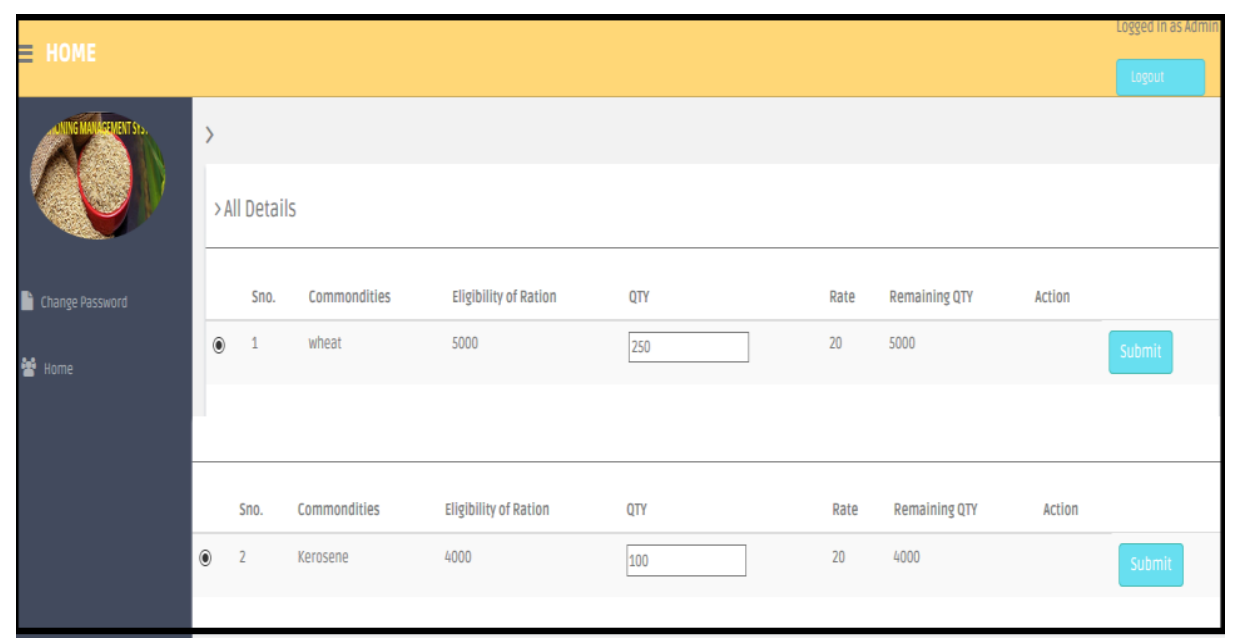

(b) Description of Commodities Page

\section{Fig. 4. Various GUI screen shots of the prototype SARDS}

\section{CONCLUSION AND FUTURE SCOPE}

The prototype of Smart Automated Ration Disbursal System (SARDS) has been demonstrated with one solid and one liquid material. The experimental trials conclude that with such a system, it is possible to automate the disbursal system end-to-end with ATM-like un-manned operation with reasonable accuracy of disbursed quantity. The experiments conducted on SARDS prove conceptually that this system can fulfill the vital need of the society to get food grains at a standard rate with convenience and help bring in transparency between users, shopkeepers and Government within the PDS by eliminating the limitations of existing system like illegal material laundering and corruption. The trials demonstrate that the automated operations also facilitate reduction in unnecessary paper work.

Many governments around the world are increasingly interested in delivering government services through internet [15]. The idea proposedin this paper will help eradicate the malpractices in the PDS by making each step work without human intervention. This will be the right step towards
e-Governance that is being presently undertaken by Indian Government since it will not only make the material distribution automatic but also the essential data collection will also happen automatic, which is a key to the future strategic planning.

As further improvements in this system, sensors that are more accurate can be used. Since the ration, shops are distributed across length and breadth of the country with huge linguistic diversity, regional language support can be provided for the GUI. Online payment can be implemented with either pre-charged card or automated deduction from

customer's bank account. Later on when other parts of PDS are brought under automated system, GPS tracking of the PDS delivery trucks, image based quality check of delivered food grain can also be done.

\section{REFERENCES}

1. Priya, B. G., \& Nikumbh, S. (2017, December). "E-Public distribution system using SMART card and GSM technology". In 2017 International 
Conference on Intelligent Sustainable Systems (ICISS) (pp. 244-249). IEEE.

2. Pingale, D., Patil, S., Gadakh, N., Avhad, R., \& Gundal, S. (2013). "Web enabled ration distribution and corruption controlling system". International Journal of Engineering and Innovative Technology (IJEIT) Volume2, (8).

3. Agarwal, M., Sharma, M., \& Singh, B. (2014, September). "Smart ration card using RFID and GSM technique". In 2014 5th International Conference-Confluence The Next Generation Information Technology Summit (Confluence) (pp. 485-489). IEEE.

4. Kurkute, S. R., Medhe, C., Revgade, A., \& Kshirsagar, A. (2016, March). "Automatic ration distribution system-A review". In 2016 3rd International Conference on Computing for Sustainable Global Development (INDIACom) (pp. 11-13). IEEE.

5. Ojha, N. (2018, January). "Radio frequency identification (rfid) technology in library: Advantages and issues". In 2018 2nd International Conference on Inventive Systems and Control (ICISC) (pp. 1206-1213). IEEE.

6. Yuan, W., Lixiu, Y., \& Fuqiang, Z. (2007, August). "A real time fingerprint recognition system based on novel fingerprint matching strategy". In 2007 8th International Conference on Electronic Measurement and Instruments (pp. 1-81). IEEE.

7. Tirthkar S, Kijbile S., Magdum S., Gaikwad P. (2017). "Android Based Ration Card System using Biometric and SMS Gateway". International Engineering Research Journal (IERJ) ,pp. 4197-4201.

8. Prasad, A., Ghenge, A., \& Zende, S. (2017, March). "Smart ration card using RFID, biometrics and SMS gateway". In 2017 International Conference on Inventive Communication and Computational Technologies (ICICCT) (pp. 347-350). IEEE.

9. Karthik, K. B. (2013). "Cloud-based ration card system using RFID and GSM technology". International Journal of Engineering Research \& Technology (IJERT), 2(4).

10. Constituting the unique Identification Authority of India, Part 1 , section 2, Gazette of India, 28th January 2009.

11. Suresh, N., Balaji, E., Anto, K. J., \& Jenith, J. (2014). "Raspberry PI based liquid flow monitoring and control". International Journal of Research in Engineering and Technology, 3(07), 122-125.

12. Monk, S. (2016). "Raspberry Pi cookbook: Software and hardware problems and solutions". " O'Reilly Media, Inc.".

13. Sidik, M., \& Ghani, S. C. (2017). "Volume Measuring System Using Arduino for Automatic Liquid Filling Machine". International Journal of Applied Engineering Research, 12(24), 14505-14509.

14. Sunehra, D., \& Goud, V. S. (2016, October). "Attendance recording and consolidation system using Arduino and Raspberry Pi". In 2016 International Conference on Signal Processing, Communication, Power and Embedded System (SCOPES) (pp. 1240-1245). IEEE.

15. Marawar, T.R., Kale, S.P., \& Araspure, K.I. (2010). "E Governance". 2010 International Conference on Data Storage and Data Engineering, 183-186. 